\title{
Study on the Combustion Process and Emissions of a Turbocharged Diesel Engine with EGR
}

\author{
Mei Deqing,, Qian Junnan,, ${ }^{1}$ Sun Ping, ${ }^{1}$ Miao Yan, ${ }^{2}$ Zhang Shuang, ${ }^{2}$ and Cai Yongjun ${ }^{2}$ \\ ${ }^{1}$ School of Automobile and Traffic Engineering, Jiangsu University, Jiangsu, Zhenjiang 212013, China \\ ${ }^{2}$ Technical Center, Powerful Machinery \& Electronics Technology Developing Co., Ltd., Jiangsu, Yancheng 224003, China
}

Correspondence should be addressed to Mei Deqing, meideqing@ujs.edu.cn

Received 30 July 2011; Revised 17 October 2011; Accepted 17 October 2011

Academic Editor: R. D. Reitz

Copyright ( $) 2012$ Mei Deqing et al. This is an open access article distributed under the Creative Commons Attribution License, which permits unrestricted use, distribution, and reproduction in any medium, provided the original work is properly cited.

\begin{abstract}
A high pressure EGR system was adopted to a turbocharged inter-cooled diesel engine, to analyze its combustion and emission characteristics under the condition of different loads and constant speed. Under the same steady operating mode, with the increase of EGR rate, the temperature of compressed gas ascended, the ignition delay was shortened, the pressure and temperature of the burned gas descended, and the combustion process was prolonged. According to the experimental data, it was found that, at the same EGR rate, lower the load of engine was, lower the temperature in cylinder, and higher the increase rate of CO was. However, the increase rate of $\mathrm{HC}$ present a falling trend. The decrease rate of the specific emission of $\mathrm{NO}_{\mathrm{x}}$ linearly varied with EGR rate with a slope of 1.651. The increase rate of smoke opacity behaved a second-order polynomial uprising trend, and the higher the load was, the sharpener the smoke opacity deteriorated, with the increase of EGR rate. From the point of emission view, the engine with EGR system can achieve the lesser exhaust emissions in some operations by adjusting the engine parameters.
\end{abstract}

\section{Introduction}

Saving oil resources and reducing the emissions of greenhouse gases have become the worldwide consensus when the earth is faced with the environment and energy sources challenges [1-3]. Direct-injection diesel engine has become the preference of commercial vehicles due to its high thermal efficiency and has been applied to 15 to 30 percent passenger cars in Euro-American markets. Meanwhile, regulations on the harmful exhaust emissions coming from engines have been increasingly stringent $[4,5]$. Turbocharging, high-pressure fuel injection, exhaust gas recirculation (EGR), electronic-control fuel supply system, and exhaust after-treatments successfully used in combination successively have become technical measures [6] to comply with emission legislations of various stages. Among technical routes to implement the emission control, the EGR system is an external device used to control $\mathrm{NO}_{\mathrm{x}}$ emissions $[7,8]$, which has been regarded as an in-engine purification measure for reorganizing the intake and adjusting the in-cylinder combustion process [9]. The mechanism of EGR system reducing $\mathrm{NO}_{\mathrm{x}}$ emissions is introducing parts of the exhaust gas into the combustion chamber to increase the heat capacity of gases, lower the temperature of burning gases, and thus reduce the $\mathrm{NO}_{\mathrm{x}}$ emission.

Because EGR would result in the combustion lag and reduced the temperature [10], there is also a possibility that the exhaust of $\mathrm{HC}, \mathrm{CO}$, and $\mathrm{PM}$ would increase in reducing $\mathrm{NO}_{\mathrm{x}}$ emissions [11]. Therefore, to achieve the best power performance of engine and the lowest emissions, it is required to figure out a proper EGR rate, by combining some other optimizing techniques with EGR [12].

Considering the cooling system of engine, the high pressure EGR method that the exhaust gas is recirculated into the intake air before reaching the turbocharger is appropriate for the turbocharged intercooled diesel engine [13]. As shown in Figure 1, the compressor and the intercooler could be avoided being polluted by the recirculated exhaust. If exhaust gases passed through the compressor and the intercooler, matters such as particulates, hydrocarbons, and sulfur in the exhaust may cause clog and corrode to the narrow passage of the cooling system. In addition, the turbocharged direct injection diesel engines applied to vehicles usually work under variable operating conditions, and the standard 


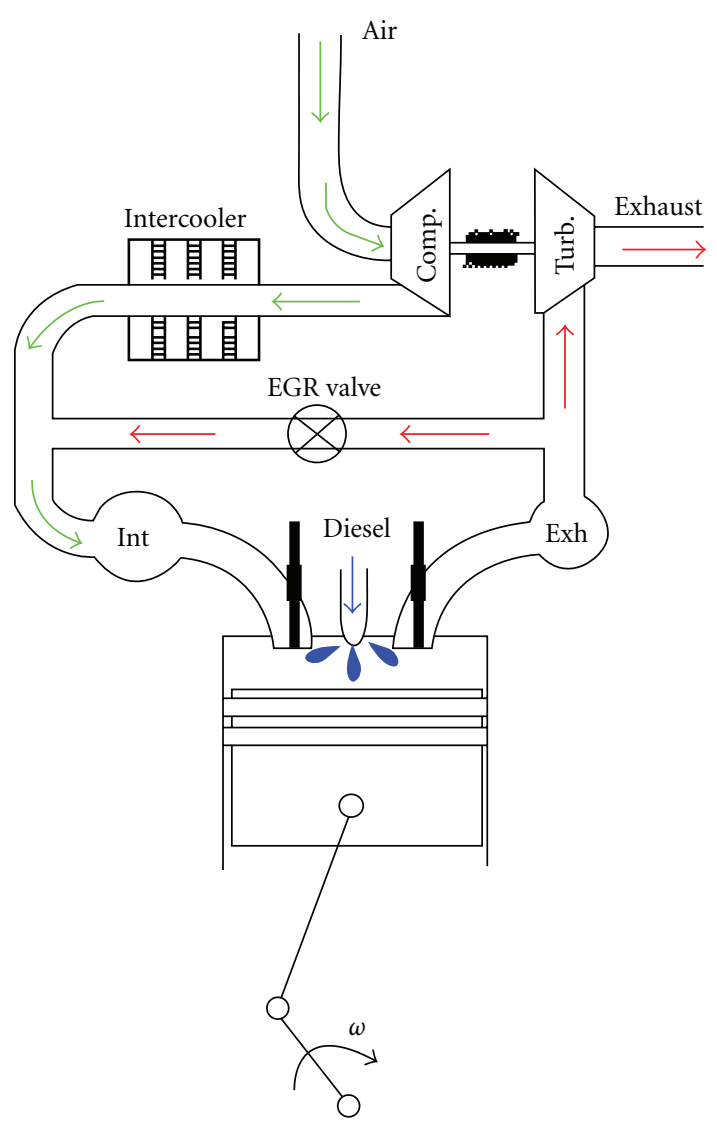

FIgURE 1: The exhaust gas recirculation system.

procedures testing emissions were also carried out under variable operating modes conditions [14]. The other EGR pattern that introduces exhaust gases into the intake air after reaching the turbocharger would delay the engine responses under the transient operating conditions, which would have an unfavorable effect on controlling the $\mathrm{NO}_{\mathrm{x}}$ emission.

\section{Test Devices and Methods}

2.1. Experimental Facilities. The engine used is a fourcylinder, turbocharged, intercooled, four-stroke, directinjection, YZ4D21 diesel engine with a bowl in piston combustion chamber. The basic data of the engine used are given in Table 1.

$\mathrm{NO}_{\mathrm{x}}$ emissions were measured using a chemiluminescent analyzer, and $\mathrm{HC}$ emissions were measured with a flame ionization detector. The working temperature of $\mathrm{HC}$ analyzer is $191^{\circ} \mathrm{C}$, and the working temperature of $\mathrm{NO}_{\mathrm{x}}$ is $110^{\circ} \mathrm{C}$. The sample gas delivered to the $\mathrm{NO}_{\mathrm{x}}$ and $\mathrm{HC}$ analyzers is not dehumidified, and so the value detected by $\mathrm{NO}_{\mathrm{x}}$ analyzer and $\mathrm{HC}$ analyzer is the kind of wet concentration. Both $\mathrm{CO}$ and $\mathrm{CO}_{2}$ were detected by nondispersive infrared analyzer but with different type, respectively. The magnetopneumatic detector was used to measure the $\mathrm{O}_{2}$ concentration. The sample gas transported to the $\mathrm{CO}, \mathrm{CO}_{2}$, and $\mathrm{O}_{2}$ analyzers was dehydrated, and the dry concentration was got. The heated sample line from the exhaust pipe to the analyzers was
TABLE 1: The basic data of the engine.

\begin{tabular}{lc}
\hline Engine type & 4-cylinder, 4-stroke, DI \\
\hline Bore & $85 \mathrm{~mm}$ \\
Stroke & $92 \mathrm{~mm}$ \\
Connect rod & $145 \mathrm{~mm}$ \\
Compression ratio & 17.5 \\
Fire order & $1-3-4-2$ \\
Rated speed & $3000 \mathrm{rpm}$ \\
Rated power & $48 \mathrm{~kW}$ \\
Fuel pump & VE4 $11 \mathrm{e} 1600 \mathrm{r} 2 \mathrm{~d} 01$ \\
Injector & KBAL-P028 \\
Static injection timing & $7^{\circ}$ CA before TDC \\
Inlet valve opening & $16^{\circ} \mathrm{CA}$ before TDC \\
Inlet valve closure & $42^{\circ} \mathrm{CA}$ after BDC \\
Exhaust valve opening & $45^{\circ} \mathrm{CA}$ before TDC \\
Exhaust valve closure & $14^{\circ} \mathrm{CA}$ after BDC \\
\hline
\end{tabular}

thermostatically controlled. The opacity of smoke emitted by a diesel engine was measured with the AVL 439 optical Hartridge smoke meter.

The main characteristics of the other instrumentations used to measure pressure, temperature, mass flow, brake power, and so forth. are listed in Table 2.

In consideration of the inappropriateness of adopting EGR at full load, operating conditions of 75\%, 50\%, 25\%, $10 \%$ loads at $1800 \mathrm{rpm}$ were chosen as the research objectives. During the test, the engine operated under a target steady condition, by adjusting the EGR valve lift, parameters of engine performance, and emissions, and the data of cylinder pressure were collected. This method guaranteed the coordination and consistency of those data. The cylinder pressure signals of 100 cycles have been collected and been averaged and smoothed mathematically. From the average pressure indicator diagrams, the heat release rate and the bulk gas temperature in cylinder were gained by calculation under the first law of thermodynamics.

2.2. The EGR Valve System. A spring-membrane valve controlled by vacuum negative pressure was adopted in EGR valve system. Besides the external inserted signals of engine performance parameter, the EGR valve system itself includes the spring membrane valve, the vacuum resource control device, and the EGR valve controller. According to the input voltage signal, the vacuum-adjusting device outputs a corresponding vacuum. And the vacuum controls EGR valve lift and manages the flow of recirculated exhaust gas as the opening power.

The EGR rate is defined with the volumetric percentage of $\mathrm{CO}_{2}$ in intake and exhaust gas:

$$
\text { EGR rate }=\frac{\varphi_{\mathrm{CO}_{2} \text { in }}}{\varphi_{\mathrm{CO}_{2} \text { exh }}} \times 100 \%
$$

In this equation, $\varphi_{\mathrm{CO}_{2}}$ in indicates the volumetric percentage of $\mathrm{CO}_{2}$ from the recirculated exhaust gas taking up of the intake and $\varphi_{\mathrm{CO}_{2}}$ exh for the volumetric percentage of $\mathrm{CO}_{2}$ in exhaust. 
TABLE 2: Basic instrumentation for pollutant emissions measurements.

\begin{tabular}{|c|c|c|c|c|}
\hline Unit & Instrumentation & Type & Accuracy & Operating principal \\
\hline Dynamometer & AVL List GmbH & AFA335 & $\pm 0.1 \%$ & Electric direct current generator \\
\hline Fuel mass flow meter & AVL List GmbH & $733 S$ & $\pm 0.1 \%$ & Coriolis effect \\
\hline Air mass flow meter & AVL List GmbH & Sensyflow & $\pm 0.1 \%$ & Hot film anemometer \\
\hline Smoke & AVL List GmbH & 439 & $\pm 0.1 \%$ & Hartridge, optical \\
\hline $\mathrm{NO}_{\mathrm{x}}$ & HORIBA & CLA-755A [wet] & $\pm 1 \%$ & Chemiluminescence detector \\
\hline $\mathrm{HC}$ & HORIBA & FIA-725A [wet] & $\pm 1 \%$ & Flame ionization detector \\
\hline $\mathrm{CO}$ & HORIBA & AIA-721 [dry] & $\pm 1 \%$ & Nondispersive infrared detector \\
\hline $\mathrm{CO}_{2}$ & HORIBA & AIA722 [dry] & $\pm 1 \%$ & Nondispersive infrared detector \\
\hline $\mathrm{O}_{2}$ & HORIBA & MPA-720 [dry] & $\pm 1 \%$ & Magnetopneumatic detector \\
\hline Combustion analyzer & DEWETRON & DEWE-800-CA-SE & & \\
\hline Piezoelectricity sensor & Kistler & $6125 \mathrm{~B} 11$ & $\pm 0.3 \%$ & \\
\hline Charge amplifier & Kistler & $\begin{array}{c}\text { DAQP-CHARGE- } \\
\text { B }\end{array}$ & time drift: $0.03 \mathrm{PC} / \mathrm{s}$ & \\
\hline Encoder & DEWETRON & CA-RIE-360 & $\pm 0.2^{\circ} \mathrm{CA}$ & \\
\hline
\end{tabular}

When the engine was steady at given loads of $1800 \mathrm{rpm}$, the flow characteristics of recirculated exhaust gas would be obtained by adjusting the EGR valve lift, as shown in Figure 2. The higher the EGR valve lift was, the larger the recirculated exhaust gas flow. Yet at different loads and the same lift of EGR valve, it was found that the lower the load of engine, the more easily the exhaust gas would be recirculated, which was presented to be the increase of recirculated exhaust gas flow as well as the EGR rate. For example, while the EGR valve kept opening at the lift of $2.5 \mathrm{~mm}$, the EGR rates were 9.5\%, 13.2\%, 18.4\%, and 20.3\%, respectively for the engine load of $75 \%, 50 \%, 25 \%$, and $10 \%$. At the same valve lift and the throttle cross-sectional area, the amount of recirculated exhaust gas depends on the pressure difference between the inlet and outlet of the EGR valve. When the engine operated at high loads, the energy conversion efficiency of exhaust gas at high pressure can be relatively high. The shaft work transferred to the compressor and increased the inlet pressure accordingly. So the pressure difference between the inlet and outlet end of EGR passage would be minor, which was unfavorable for exhaust gas flowing into intake system. Hence higher the load of engine, lesser would be the EGR. That is why sometimes the EGR may be hard to achieve under the conditions of full load at low speed.

\section{Analysis of Combustion Characteristics of Diesel Engines with EGR}

As shown in Figure 3, owning to the reduced fresh intake, the fresh intake reduced and the air excess ratio descended linearly as EGR rate increased. But the effective specific fuel consumption stayed invariant or fluctuated a little. In this graph, BMEP is used to indicate the brake mean effective pressure in various given operating conditions at $1800 \mathrm{rpm}$ engine speed. The operating condition illustrations in Figures $6,7,9,11$ subsequently are identical to those in Figure 3.

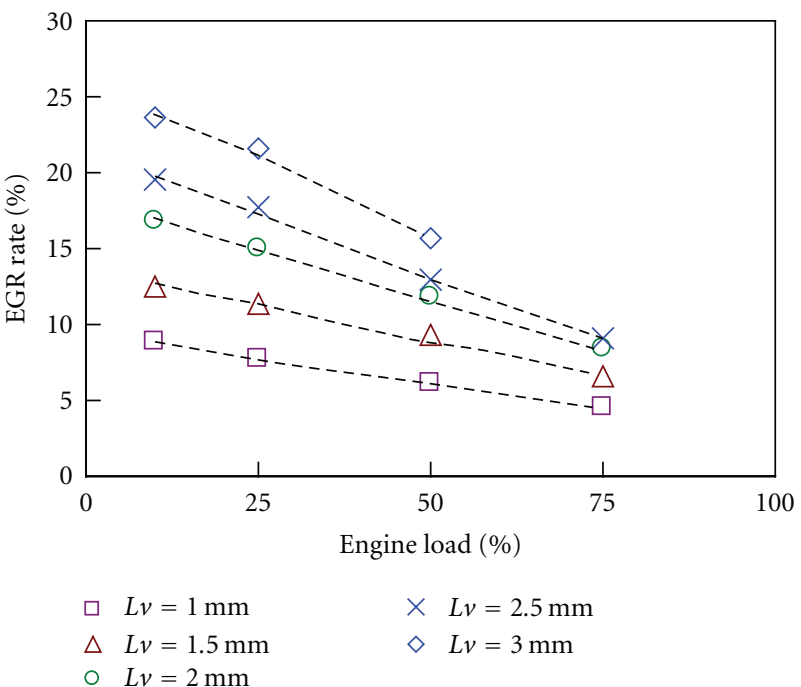

Figure 2: Flow characteristics of EGR valve.

The introduced exhaust gas flow increased with increasing EGR valve lift, but the maximum explosive pressure of the burned gas declined. The EGR rate and its impact on combustion characteristics, at the BEMP of $0.67 \mathrm{Mpa}$ and the speed of $1800 \mathrm{rpm}$, have been indicated and analyzed in Figure 4. In the pressure indicator diagram, Figure 4(a), when the EGR rate rose to $9.5 \%$, the crank angle to the maximum explosive pressure was about $2^{\circ} \mathrm{CA}$ in advance. And the maximum pressure with the EGR rate of $9.5 \%$ dropped 2.2\% down compared to the case without EGR. With the increase of EGR, the pressure rise rate, as shown in Figure 4(b), reduced and its corresponding crank angle retarded. And the peak of pressure rise rate with the EGR rate of $9.5 \%$ fell down $26.8 \%$ as to the case without EGR. In the region marked with a circle, the point at which the curve of pressure rise rate turned up abruptly can indicate the start of ignition, for the reason that the curve of pressure 


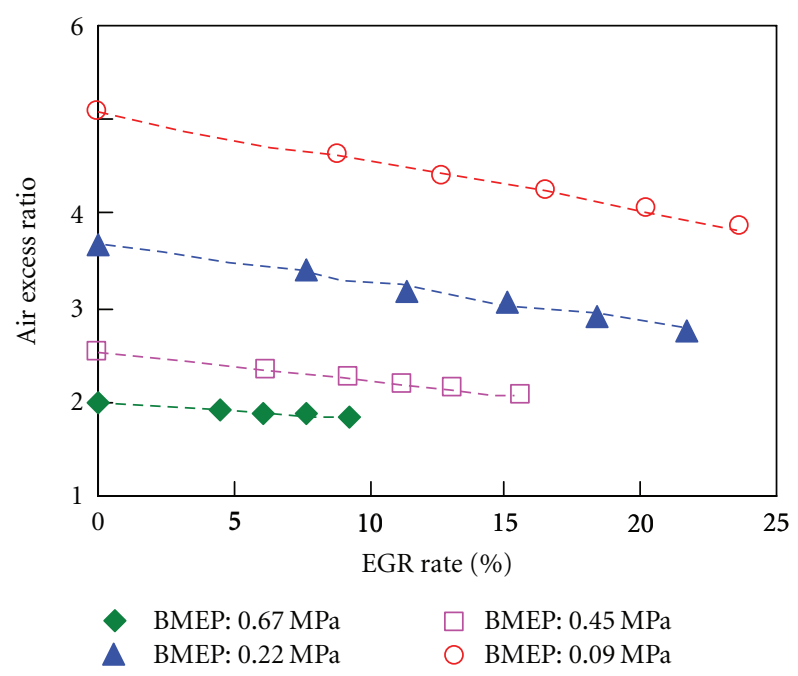

FIGURE 3: Effects of EGR on the air excess ratio.

rise rate would fall down smoothly in the exact marked area if there was no fire in cylinder. According to this criterion, the ignition of the case with the EGR rate of $9.5 \%$ occurred about $1.5^{\circ} \mathrm{CA}$ earlier than the case without EGR.

In Figure 4(c), with the increase of EGR rate, ignition occurred in advance and the initial peak of heat release rate reduced, and the maximum decrease rate of the initial peak of heat release was $18.3 \%$ with the EGR rate of $9.5 \%$. The ignition delay of diesel engine mainly depends on the nature of the fuel, the concentration of the mixtures and its corresponding temperature and pressure conditions. After the EGR was introduced, the air-fuel ratio and the oxygen concentration of mixtures, decreased, and the inert gas increased, which may increase the ignition delay. However, the recirculated gas raised the intake temperature as well as the bulk gas temperature in cylinder at the end of compression, in Figure 4(e). And the curve of transient heat release rate in Figure 4(c) has indicated that heat released obviously earlier under heavy EGR. It is obtained from the above that the oxygen concentration of mixtures would not affect the ignition delay much as the temperature did and a higher EGR rate would be favorable to shorten the ignition delay [15].

At low loads, the intake temperature was the main factor affecting the ignition delay [16]. Due to the little fuel supply in that condition, the basic data of air excess ratio was large enough to have little effect on the ignition delay, although the air excess ratio could descend with the increase of EGR rate. Also, it could be deduced from the above that the decrease of ignition delay would be much more remarkable for the distinct warming effect of intake at low loads with high EGR rate.

Although without EGR the mixture ignition would begin a bit later, once that happened the accumulative heat release would increase fast, as shown in Figure 4(d). The inert atmosphere and the specific heat capacity have been increased due to recirculated exhaust gas; in other words, the combustion can be delayed. With higher EGR rate, the peak temperature of combustion distinctly declined. And the bulk gas temperature curve has also reflected a disadvantage of EGR that the combustion duration was prolonged and the exhaust temperature, as shown in Figure 5, increased accordingly. An excess EGR rate could cause combustion deterioration in cylinder. So to achieve an optimal control of combustion and emission, a reasonable EGR rate value should be figured out, according to various operating conditions.

\section{Effects of EGR on the Emission Characteristics of Diesel Engines}

4.1. Characteristics of $\mathrm{NO}_{x}$ Emission. The above-mentioned analysis of the combustion process of diesel engines with EGR has shown that EGR would shorten ignition delay, increase the specific heat capacity of the working medium in cylinder, reduce the heat released in the period of premixed combustion, lower the in-cylinder temperature of combustion, and decrease the oxygen concentration of intake simultaneously; all of which would play an active role in restraining the generation of $\mathrm{NO}_{\mathrm{x}}$ in cylinder. So as not to deteriorate the engine performance, the value of EGR rate should remain lower at high and medium loads and increase moderately at low loads.

Figure 6 has shown that, at various loads of $1800 \mathrm{rpm}$ engine speed, the specific emission of $\mathrm{NO}_{\mathrm{x}}$ decreased with the increase of EGR rate. As the revision of test conditions including temperature, humidity of the testing spot, and the data deviation of the given operating parameters (speed, torque, etc.) has been considered, it is reasonable to take the specific emission as a standard for assessing engine performance.

How the specific emission of $\mathrm{NO}_{\mathrm{x}}$ changed when the EGR rate increased is shown in Figure 6(a). At the top of Figure $6(\mathrm{a})$, the fitting curve for the points of $10 \%$ load can be rounded to a linear function with a slope of -0.148 and an intercept of 10.538. The points below indicated how the specific emission of $\mathrm{NO}_{\mathrm{x}}$ changed with EGR rate at 75, 50, and 25 percent loads, respectively. After integration, those points can be fitted into a curve with a slope of -0.145 and an intercept of 7.372. Seen from this graph, the slopes of these two curves are approximately equal. So it is clear that at different loads, the decrease rate of the specific emission of $\mathrm{NO}_{\mathrm{x}}$ varied with EGR rate with a linear slope of 1.651, as shown in Figure 6(b).

4.2. Emission Characteristics of Smoke Opacity. Figure 7(a) has shown how the smoke opacity changed with EGR rate at different loads of $1800 \mathrm{rpm}$ engine speed. Generally speaking, introducing exhaust gas would lower the oxygen concentration in intake and cause the increase of the smoke opacity. It can be seen from Figure 7(b) that on the whole the relation between the smoke opacity and the EGR rate presented a second-order polynomial relation. At medium and high loads at which basic value of the air excess ratio is relatively low, smoke opacity changed a lot even if the air excess ratio changed a little. As EGR rate increased, the 


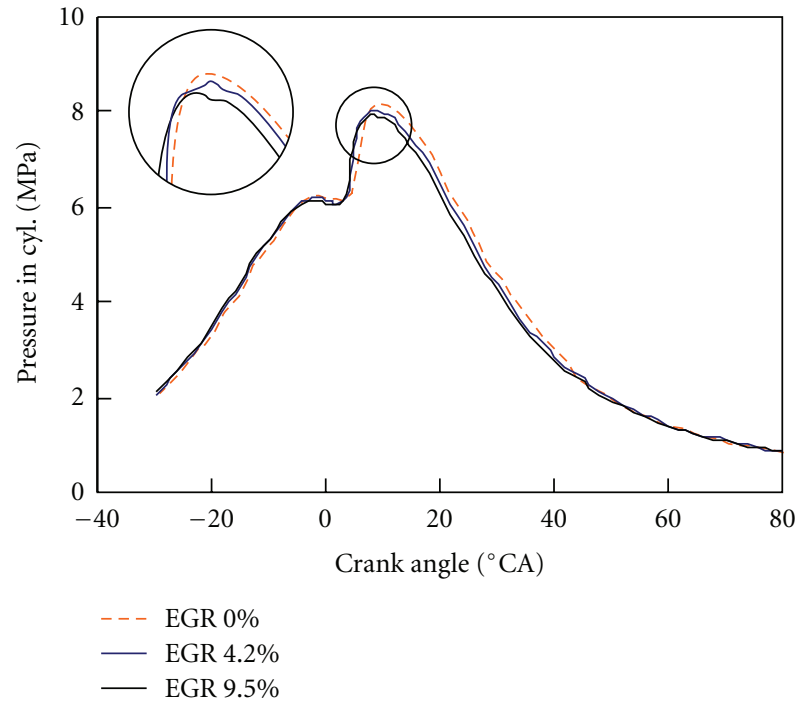

(a) Pressure in cylinder

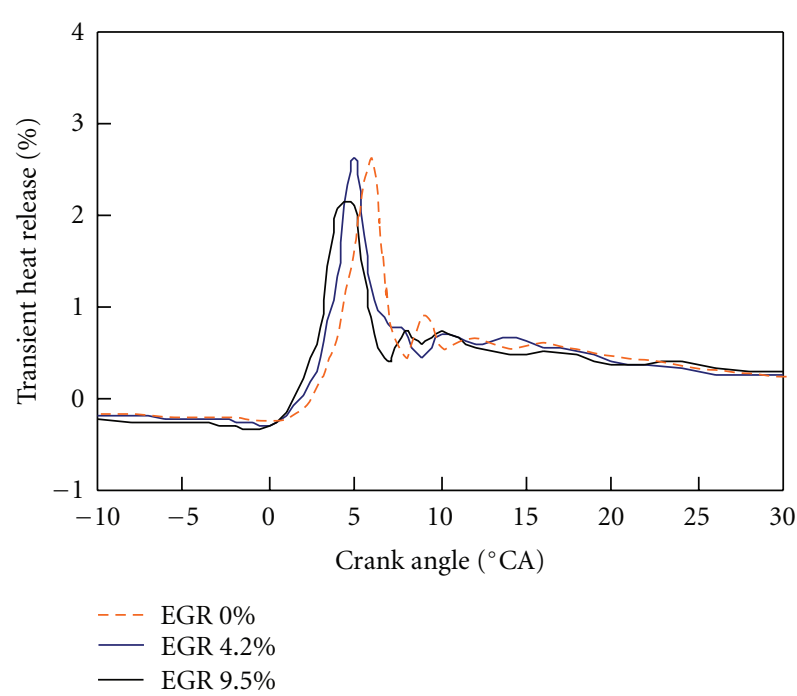

(c) Transient heat release rate

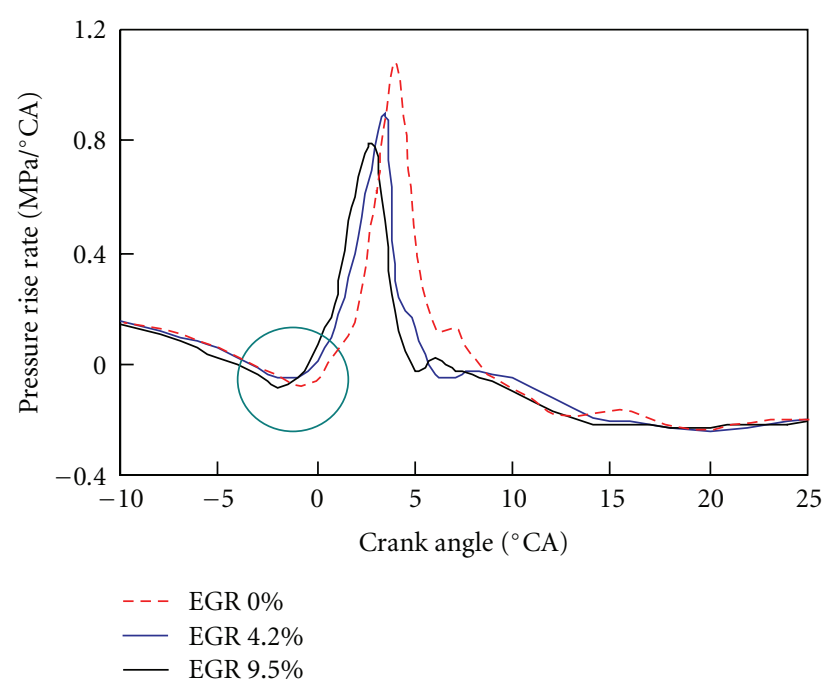

(b) Pressure rise rate

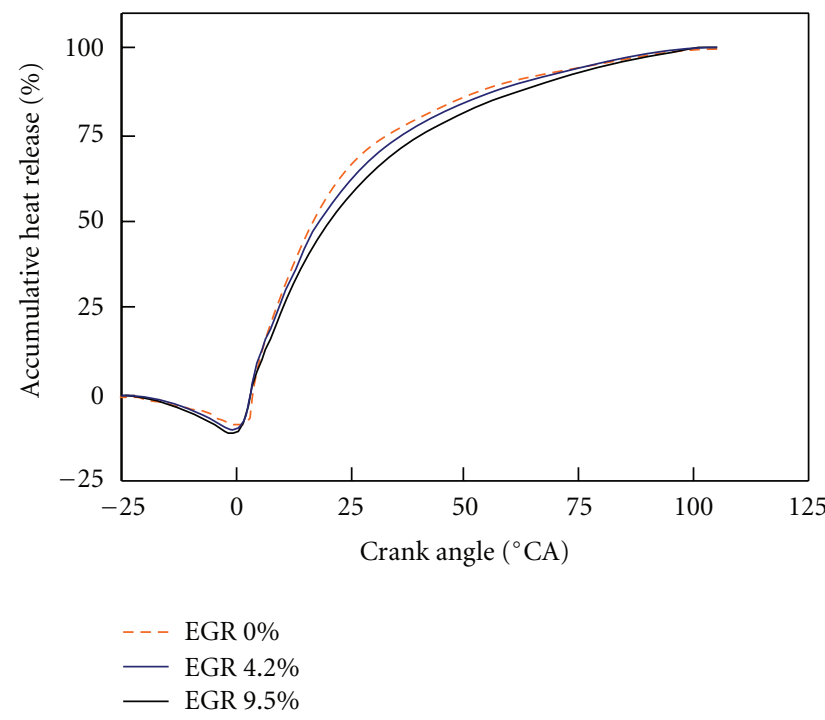

(d) Accumulative heat release rate

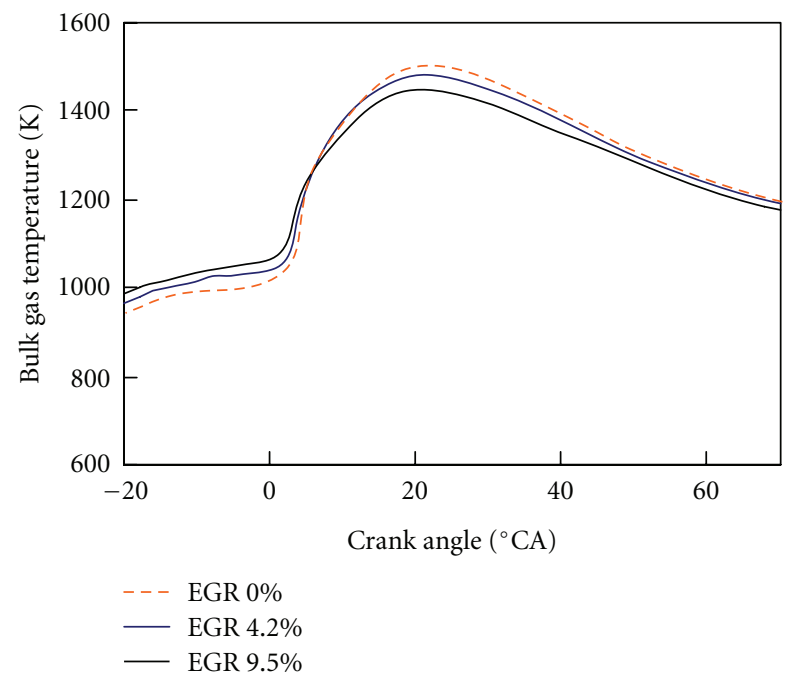

(e) Bulk gas temperature

FIGURE 4: The combustion characteristic parameters of diesel engine with EGR. 


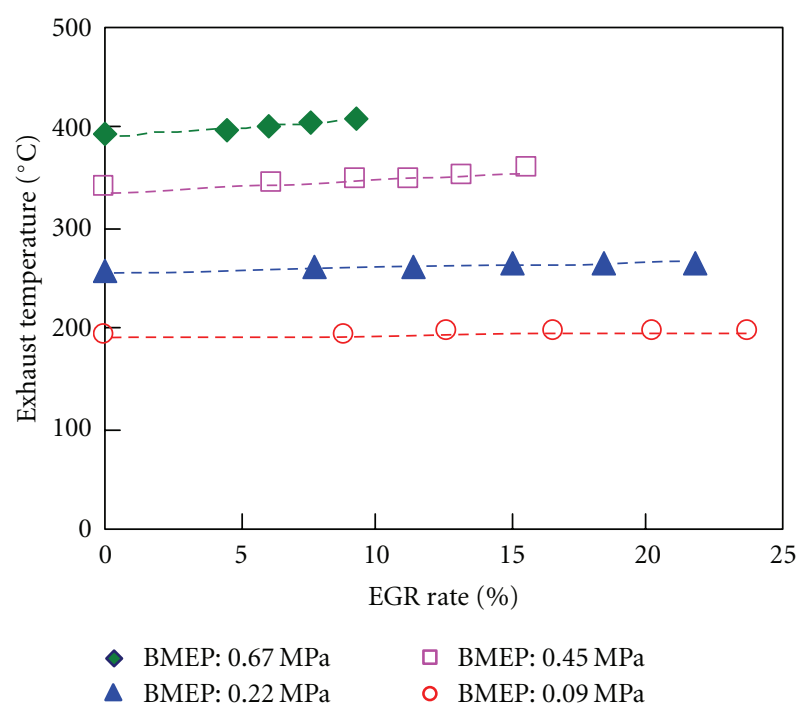

FIgUre 5: The exhaust temperature of different modes.

smoke opacity increased fast and deteriorated sharply, while at low loads, the influence of EGR rate on the air excess ratio weakened due to higher air excess ratio cardinality and the trend of smoke deterioration also declined. In addition, in Figure 7(b), as EGR rate increased, the curves of high and medium loads have larger slopes than that of low loads. For that reason the value of EGR rate should be limited at high loads.

4.3. Characteristics of CO Emission. The generation of CO, which was abided by the chemical reaction dynamics, took a long time. And the bulk gas temperature played a key effect on the formation of CO. As the amount of recirculated exhaust gas increased, the temperature of combustion and the required oxygen concentration in cylinder declined, and consequently the concentration of $\mathrm{CO}$ rose. The illustration of [L] in Figure 8 corresponds to the left coordinate axis, and $[R]$ vice versa. In the graph, all the data oriented to the right coordinate axis are indicated with leading arrows. At the right coordinate axis, $\varphi$ means the volumetric concentration, which can also apply to the following figures. Figure 8(a) has enumerated, at high and medium loads of $1800 \mathrm{rpm}$ engine speed, how the specific emission of $\mathrm{CO}$ and the volumetric concentration changed with EGR rate. The counterparts at the two respective low loads have been illustrated in Figure 8(b). It can be observed that with the increase of EGR rate, the volumetric percentage of $\mathrm{CO}$ increased and the specific emission of $\mathrm{CO}$ declined. The adoption of EGR declined the gross of exhaust reaching into the atmosphere. The specific emission of CO significantly reflected the increase of $\mathrm{CO}$ volumetric concentration and the decrease of exhaust flow.

The increase rate of $\mathrm{CO}$ volumetric concentration varied with EGR rate, at different loads of $1800 \mathrm{rpm}$ speed, which has been shown in Figure 9. The point marked with a circle in the graph is used to interpret the increase rate of $\mathrm{CO}$ volumetric concentration. Here, the increase rate of $\mathrm{CO}$

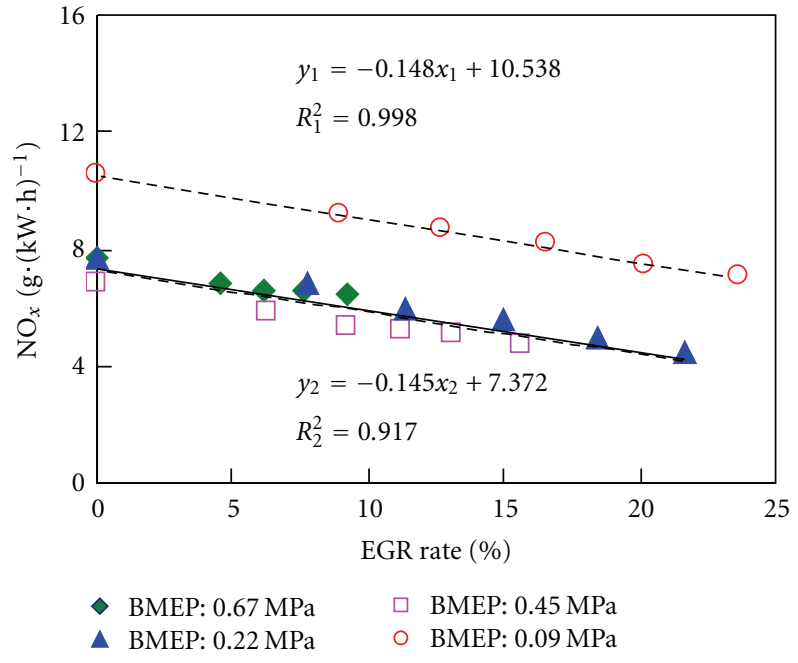

(a) Specific emission of $\mathrm{NO}_{\mathrm{x}}$

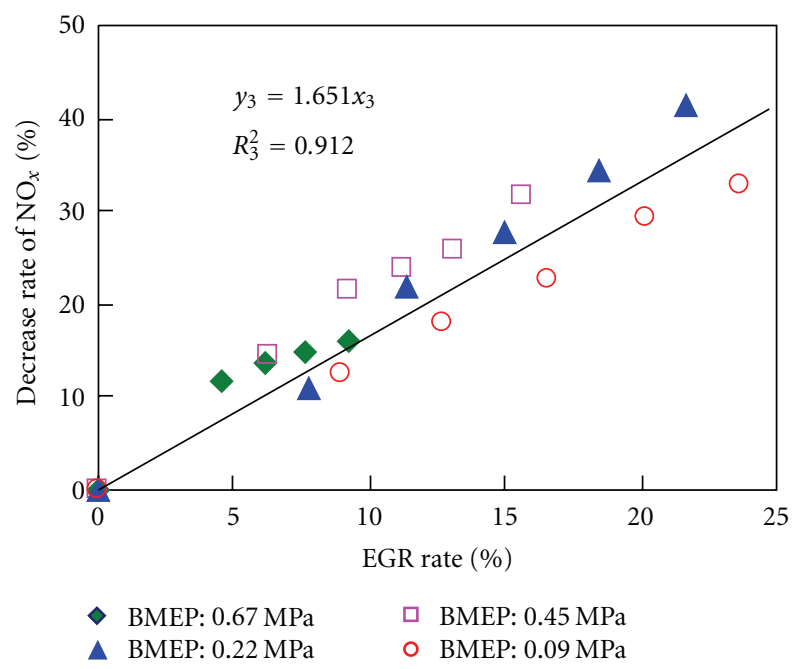

(b) Decrease rate of $\mathrm{NO}_{\mathrm{x}}$

FIgURE 6: The specific emissions of $\mathrm{NO}_{\mathrm{x}}$ varying with EGR rate.

means the percentage of the added amount of $\mathrm{CO}$ volumetric concentration, with the EGR rate of $20.7 \%$ relative to the original $\mathrm{CO}$ volumetric concentration without EGR at that operation mode. However, the increase of EGR rate means the decrease of the exhaust gross. As shown in Figure 8, the specific emission of $\mathrm{CO}$ decreased with the increase of EGR rate, because the $\mathrm{CO}$ volumetric concentration increased less fast than EGR rate did. Thereafter, the effect of engine load on the $\mathrm{CO}$ volumetric concentration changing with EGR rate needs to be discussed. It can be seen from Figure 9 that the linear slopes of the increase rate of CO to EGR rate were $0.727,0.730,0.814$, and 0.892 for the load of engine of $75 \%, 50 \%, 25 \%$, and $10 \%$, respectively, within order. The increase rate of $\mathrm{CO}$ volumetric concentration behaved a rising trend compared with EGR rate as the load of engine declined. The reason was that when the engine was at low loads, the bulk gas temperature in cylinder was also relatively low. But the temperature of combustion 


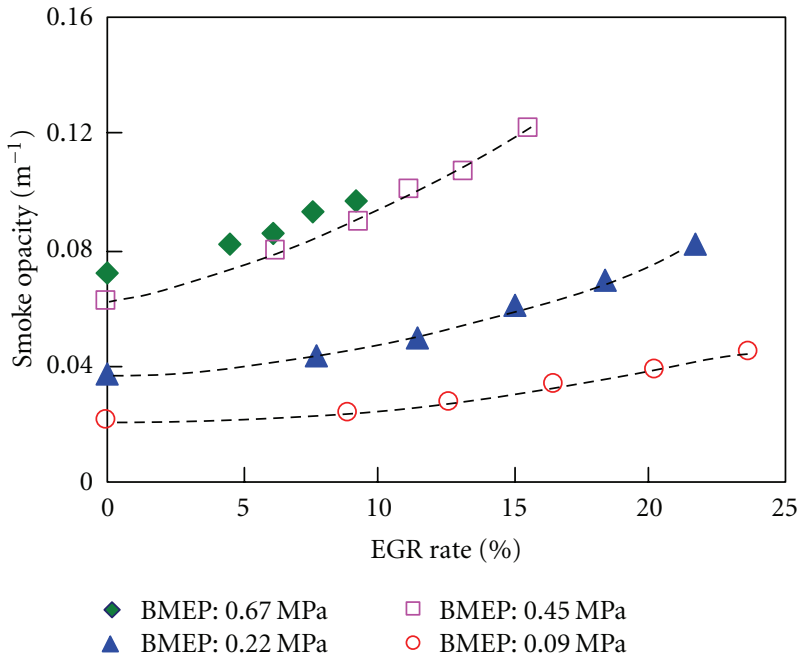

(a) Smoke opacity

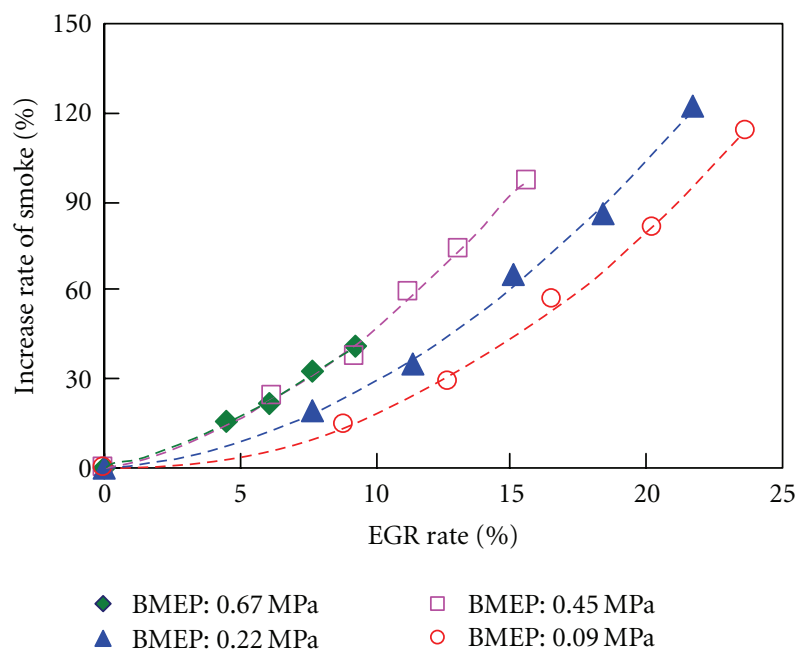

(b) Increase rate of smoke

FIGURE 7: Effects of EGR rate on the smoke feature.

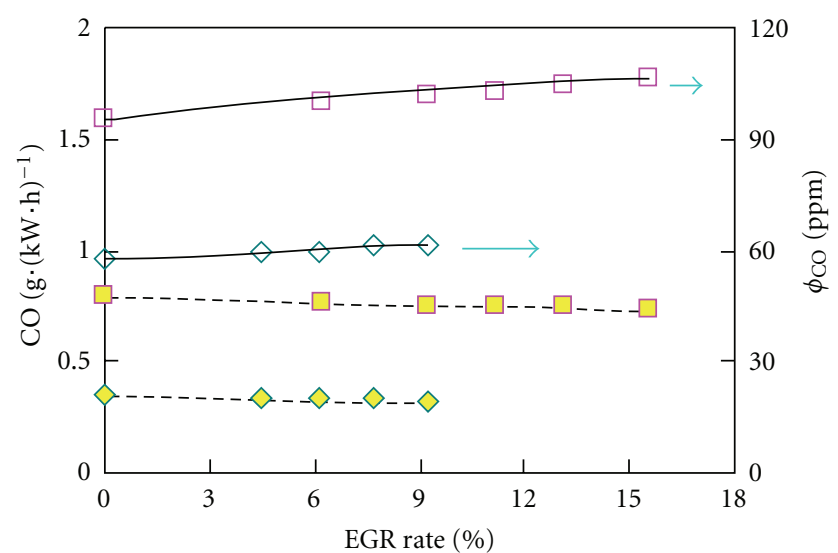

$\begin{array}{ll}\diamond \text { BMEP: 0.67 MPa [L] } & \diamond \text { BMEP: 0.67 MPa [R] } \\ \square \text { BMEP: 0.45 MPa [L] } & \square \text { BMEP: 0.45 MPa [R] }\end{array}$

(a) Medium and high loads

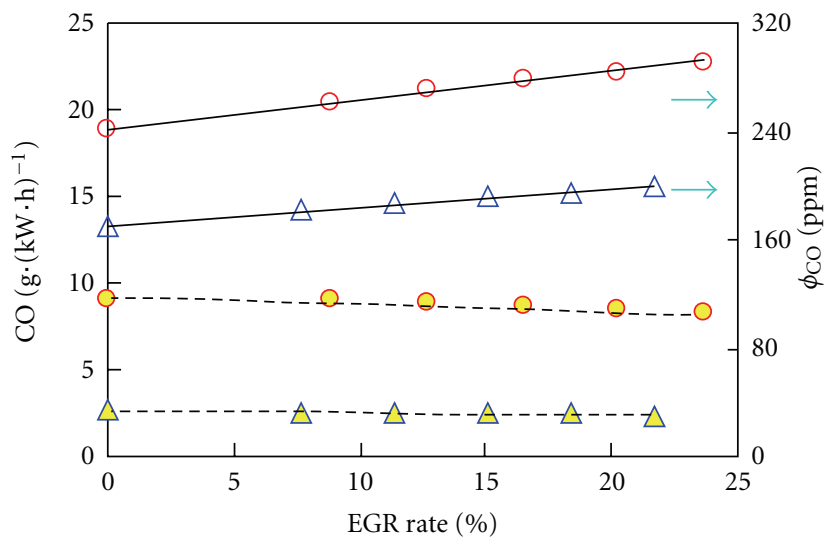

$\begin{array}{lll}\triangle \text { BMEP: } 0.22 \mathrm{MPa} \text { [L] } & \triangle \text { BMEP: 0.22 MPa [R] } \\ \bigcirc \text { BMEP: 0.09 MPa [L] } & \bigcirc \text { BMEP: 0.09 MPa [R] }\end{array}$

(b) Low loads

FIGURE 8: Effects of EGR on the CO emission.

affected the generation of $\mathrm{CO}$ remarkably. The increase rate of $\mathrm{CO}$ volumetric concentration was less than the rate at which the EGR increased. The slope of the increase rate was less than but close to 1.0, in Figure 9, at low loads, and, imaginably, the specific emission of CO may keep the same level approximately.

4.4. Characteristics of HC Emission. As EGR rate increased, the trend of the $\mathrm{HC}$ volumetric concentration is similar to the reported CO trends. Figure 10 has shown how the specific emission and the $\mathrm{HC}$ volumetric concentration changed with EGR rate, under the condition of four respective loads of $1800 \mathrm{rpm}$ speed. As shown in Figure 10(a), although the exhaust gross decreased, the specific emission of $\mathrm{HC}$ rose a little with the increase of EGR rate at the high and medium loads, for the HC volumetric concentration increased dramatically. Nevertheless, the specific emission of $\mathrm{HC}$ is on the contrary, as shown in Figure 10(b), which behaved a descending trend with the increase of EGR rate at low loads, although the $\mathrm{HC}$ volumetric concentration increased as usual.

The HC emissions derived from the thinnest mixtures which cannot be ignited during the ignition delay. Therefore the $\mathrm{HC}$ emissions were related to the ignition delay. At low loads, the more the recirculated exhaust gas was, the better the effect of heating intake, the shorter the ignition delay, and the more beneficial for reducing HC.

The HC emissions were also a product of incomplete combustion, thus closely related to the oxygen concentration of mixtures. As stated before, at medium and high loads the basic value of the air excess ratio was relatively small, and the decrease of oxygen concentration caused by EGR 


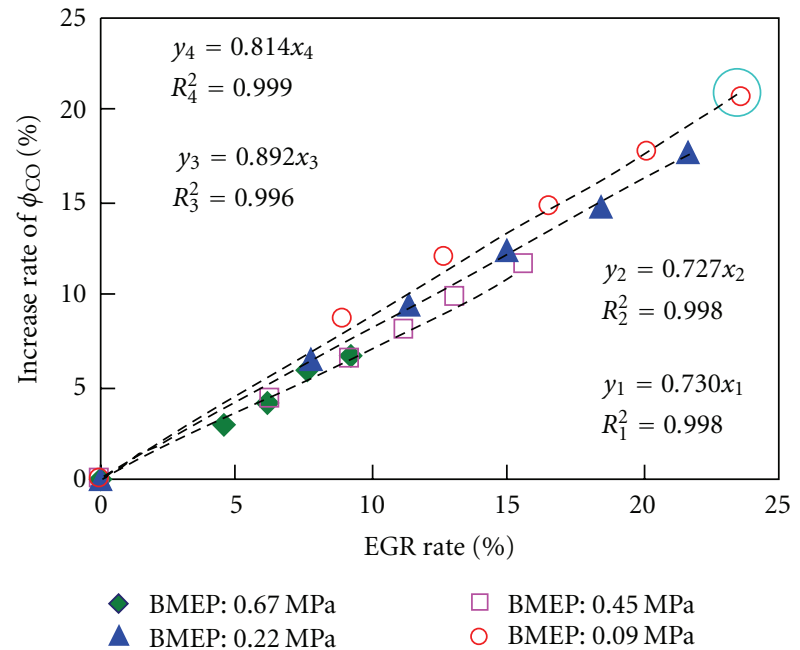

FIGURE 9: The CO volumetric concentration increasing feature with EGR rate.

affected the $\mathrm{HC}$ emissions exquisitely. While at low loads, the inert atmosphere caused by EGR would not affect the HC emissions as much as it did at medium and high loads.

Figure 11 has shown, at different loads, how the rate increase of $\mathrm{HC}$ volumetric concentration varied with EGR rate. And the meaning of the increase rate of $\mathrm{HC}$ volumetric concentration can be referred back to the interpretation of the increase rate of $\mathrm{CO}$ volumetric concentration. It can be seen from Figure 11 that the linear slopes of the increase rate of HC to EGR rate were 1.348, 1.241, 0.570, and 0.357 for the load of engine of $75 \%, 50 \%, 25 \%$, and $10 \%$, respectively, within order. EGR would cause the reduction of oxygen concentration and ignition delay, thus as EGR rate increased the $\mathrm{HC}$ volumetric concentration increased rapidly at high and medium loads while it tended to increase slowly at low loads. In the former case, the HC volumetric concentration increased even faster than EGR rate. And in the latter one, the contrary was the case. Therefore it could be inferred that the specific emission of HC would increase with EGR rate at high loads; on the other hand, the specific emission of HC would reduce with increase of EGR rate at low loads.

Generally, the specific emission of $\mathrm{HC}$ and $\mathrm{CO}$ was determined by not only the volumetric concentration, which would increase due to EGR rate, but also the volumetric exhaust flow, on the contrary which would decrease due to EGR rate. Whether the increase rate of $\mathrm{HC}$ and $\mathrm{CO}$ volumetric concentration would outweigh the increase of EGR rate or not would dominate the trend of the specific emission of HC and CO. According to the experimental data, the slope of the increase rate of $\mathrm{HC}$ volumetric concentration with same EGR rate at each load would decline when the engine's load declined; however the increase rate of $\mathrm{CO}$ behaved completely reversely, and the reason has been narrated previously by connecting the characteristics of combustion process with EGR.

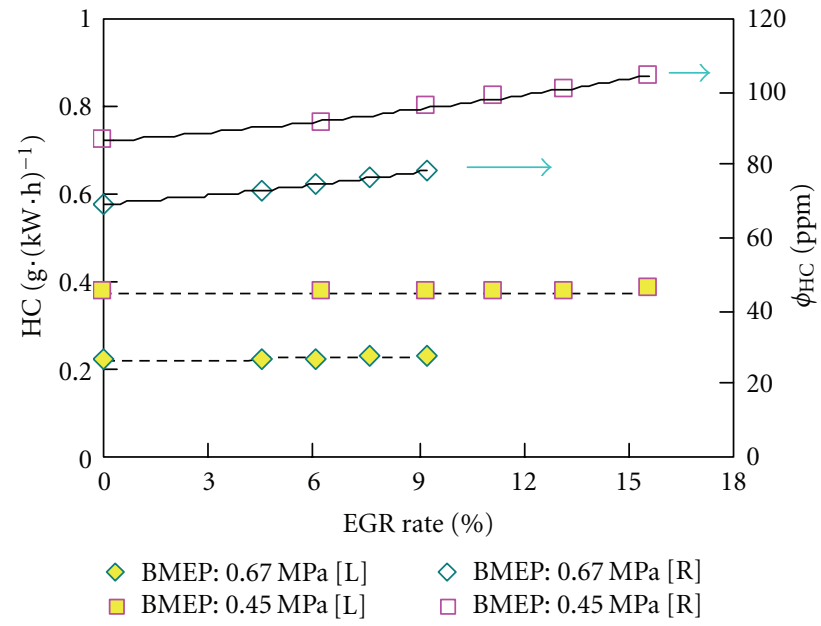

(a) Medium and high loads

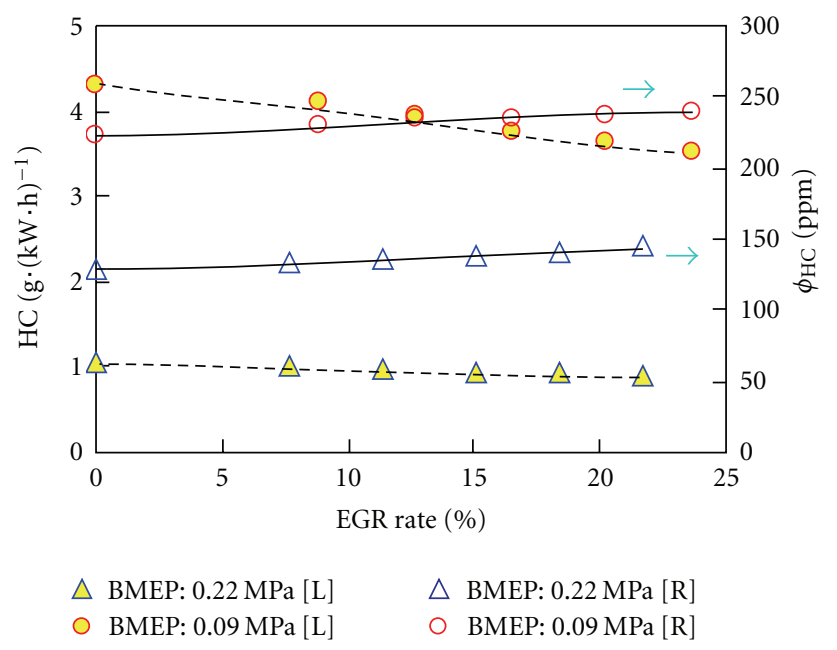

(b) Low loads

FIgURE 10: Effects of EGR rate on the HC emissions.

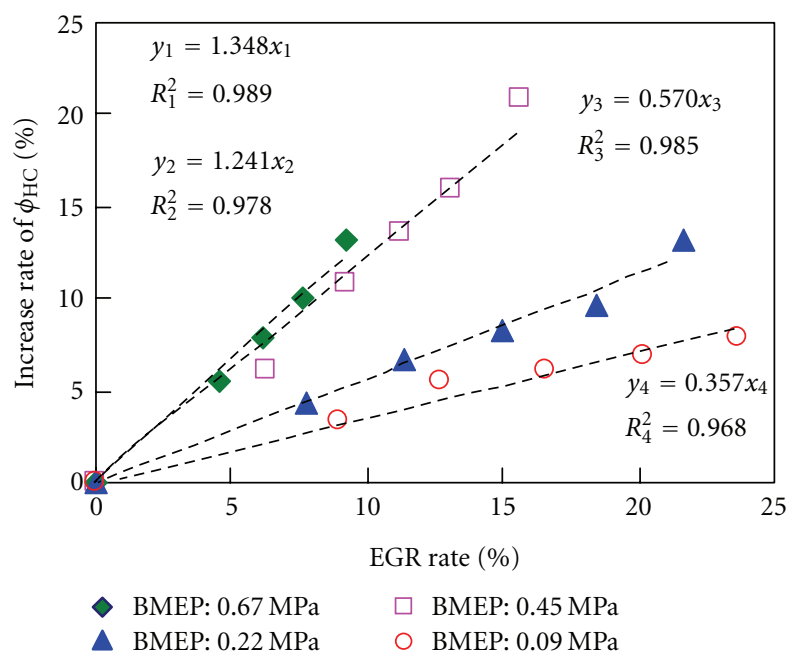

FIGURE 11: The HC volumetric concentration increasing feature with EGR rate. 


\section{Summary/Conclusion}

(1) At constant speed and the same lift of EGR valve, the flow of exhaust decreased as the load declined. But the amount of recirculated exhaust gas increased, and EGR rate augmented distinctly. As the lift of the EGR valve increased, the maximum explosive pressure decreased, and the crank angle of the maximum pressure moved towards the top dead center. The increase of the EGR rate resulted in the rise of intake temperature which shortened the ignition delay and at the same time the peak of pressure rise rate, the initial peak of heat release and the incylinder temperature of combustion lowered, and the combustion delayed.

(2) In the condition of moderate EGR rate, the specific emission of $\mathrm{NO}_{\mathrm{x}}$ decreased almost linearly as EGR rate increased. The relationship between the decrease rate of the specific emission of $\mathrm{NO}_{\mathrm{x}}$ and EGR rate can be linearly rounded with a slope of 1.651 . However, the increase rate of smoke opacity behaved a second-order polynomial uprising trend, and the higher the load was, the sharpener the smoke opacity deteriorated, with the increase of EGR rate.

(3) The generation of CO was subject to bulk gas temperature. With the increase of EGR rate, the in-cylinder temperature of combustion decreased obviously under the conditions of low loads, so the increase rate of $\mathrm{CO}$ volumetric concentration augmented within an uprising order of slopes of $0.727,0.730,0.814$, and 0.892 , when the load of engine declined with an order of engine loads of $75 \%$, $50 \%, 25 \%$, and $10 \%$.

(4) As the reduction of ignition delay and the decrease of oxygen concentration caused by EGR were considered as two factors affecting the $\mathrm{HC}$ emission, the increase rate of $\mathrm{HC}$ volumetric emission declined within a declining order of slopes of 1.348, 1.241, 0.570 , and 0.357 , when the load of engine declined with an order of engine loads of $75 \%, 50 \%, 25 \%$, and $10 \%$.

\section{Acknowledgment}

The authors wish to express their appreciation for the funding from the National Natural Science Foundation of China (no. 50976051), which supported this study.

\section{References}

[1] T. A. Boden, G. Marland, and R. J. Andres, Global, Regional, and National Fossil-Fuel $\mathrm{CO}_{2}$ Emissions, Carbon Dioxide Information Analysis Center, Oak Ridge National Laboratory, U.S. Department of Energy, Oak Ridge, Tenn, USA, 2009.

[2] R. Ewing, A. C. Nelson, K. Bartholomew, P. Emmi, and B. Appleyard, "Response to special report 298 driving and the built environment: the effects of compact development on motorized travel, energy use, and $\mathrm{CO}_{2}$ emissions," Journal of Urbanism, vol. 4, no. 1, pp. 1-5, 2011.
[3] Z. Songli, "The effect of diesel vehicle on saving energy and cutting greenhouse gas," Energy Conservation And Environmental Protection, vol. 7, pp. 9-11, 2006.

[4] G. F. Allen and M. Lewis, "Finding the proper forum for regulation of u.s. greenhouse gas emissions: the legal and economic implications of massachusetts v. EPA," envisioning energymarch, 44 U. Rich. L. Rev. 919, 2010.

[5] J. McCarthy, "EPA regulation of greenhouse gases: congressional responses and options," 2010.

[6] H. Zhiyu, C. Zheng, L. Jingping, and L. Yun, "Modern diesel engine technology for passenger cars," Engineering Sciences, pp. 36-38, 2009.

[7] E. Rajasekar, A. Murugesan, R. Subramanian, and N. Nedunchezhian, "Review of $\mathrm{NO}_{x}$ reduction technologies in $\mathrm{CI}$ engines fuelled with oxygenated biomass fuels," Renewable and Sustainable Energy Reviews, vol. 14, no. 7, pp. 2113-2121, 2010.

[8] Z. Zhendong, C. Chaomei, and Z. Ping, "Design of an EGR control system for a supercharged direct-injection diesel egnine," Automotive-Engineering, vol. 26, no. 2, pp. 136-138, 2004.

[9] H. Wenjun, "Application of EGR technology on diesel engine," Small Internal Combustion Engine and Motorcycle, vol. 37, no. 1, pp. 75-78, 2008.

[10] M. Fathia, R. K. Sarayb, and M. D. Checkelc, "The influence of exhaust gas recirculation (EGR) on combustion and emissions of n-heptane/natural gas fueled homogeneous charge compression ignition (HCCI) engines," Applied Energy Journal, vol. 10, p. 1016, 2011.

[11] G. Changming, Y. Shufangetc et al., "Emission characteristics of automobile turbocharged diesel engine with EGR," Transactions of The Chinese Society for Agricultural Machinery, vol. 36, no. 4, pp. 144-146, 2005.

[12] S. O. Wasiu, S. A. Sulaiman, and A. R. A. Aziz, "An experimental study of different effects of EGR rates on the performance and exhaust emissions of the stratified charge piston direct injection compressed natural gas engine," Journal of Applied Sciences, vol. 11, no. 9, pp. 1479-1490, 2011.

[13] F. Zuhua, L. guihua, and S. Guanping, "The structure plans and key technologies of EGR system in turbo-charged, directinjected diesel engines," Internal Combustion Engines, vol. 3, pp. 15-17, 2003..

[14] K. Anand, R. P. Sharma, and P. S. Mehta, "Experimental investigations on combustion, performance, and emissions characteristics of a neat biodiesel-fuelled, turbocharged, direct injection diesel engine," Journal of Automobile Engineering, vol. 224, no. 5, pp. 661-679, 2010.

[15] N. Ladommatos, S. M. Abdelhalim, H. Zhao, and Z. Hu, "The effects on diesel combustion and emissions of reducing inlet charge mass due to thermal throttling with hot EGR," in Proceedings of the SAE International Congress \& Exposition, pp. 97-109, February 1998.

[16] A. K. Sarangi, G. P. McTaggart-Cowan, and C. P. Garner, "The effects of intake pressure on high EGR low temperature diesel engine combustion," in Proceedings of the SAE Powertrains Fuels \& Lubricants Meeting, San Diego, CA, USA, October 2010. 

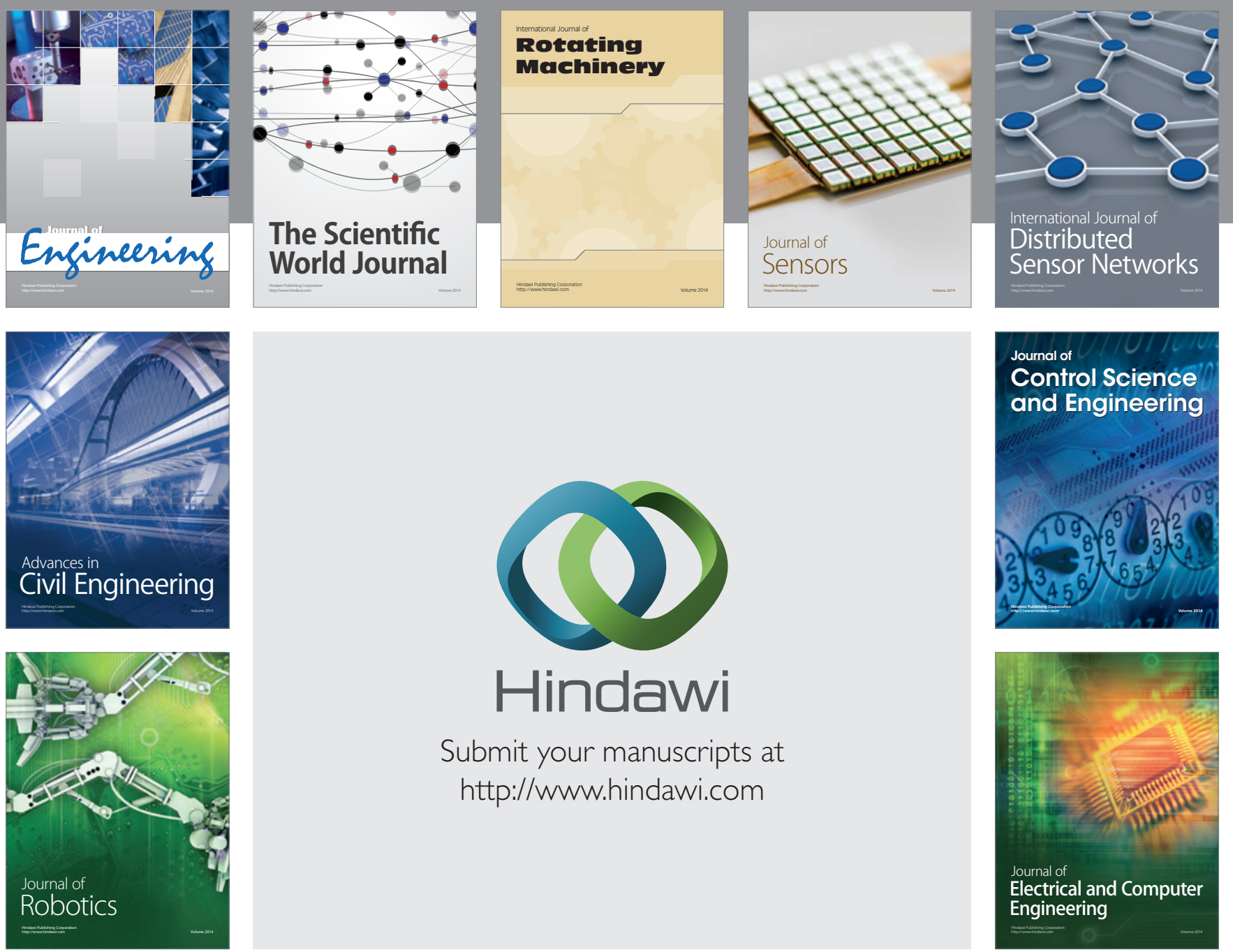

Submit your manuscripts at

http://www.hindawi.com
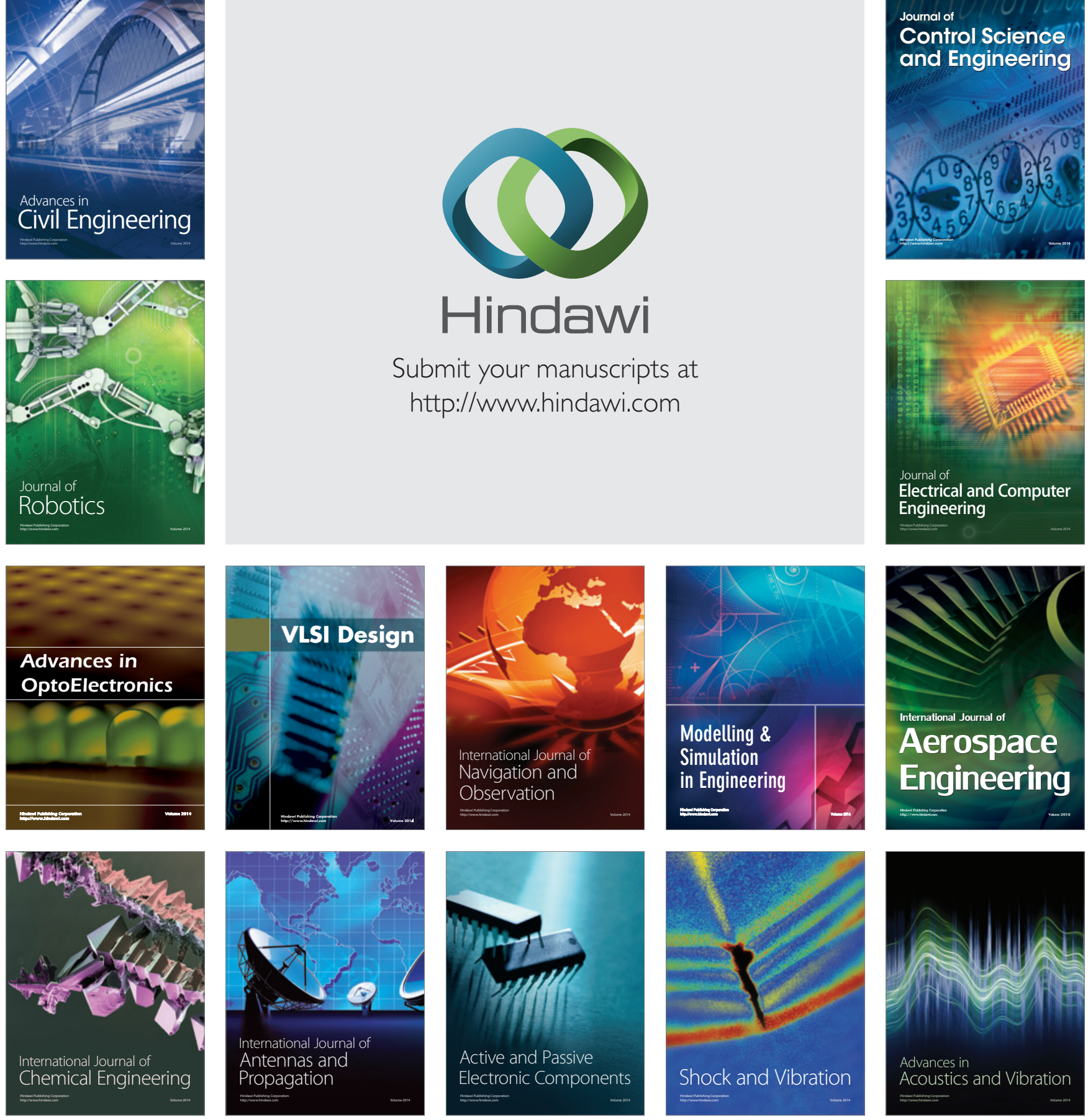